BLANCHET, Luiz Alberto; BACELLAR, Roberto Ramos. Desafios do direito administrativo no estado regulador. Revista Eletrônica Direito e Política, Programa de Pós-Graduação Stricto Sensu em Ciência Jurídica da UNIVALI, Itajaí, v.12, n.3, 30 quadrimestre de 2017. Disponível em: www.univali.br/direitoepolitica - ISSN 1980-7791

\title{
DESAFIOS DO DIREITO ADMINISTRATIVO NO ESTADO REGULADOR
}

\author{
ADMINISTRATIVE LAW CHALLENGES IN THE REGULATORY STATE
}

Luiz Alberto Blanchet ${ }^{1}$

Roberto Ramos Bacellar²

SUMÁRIO: Introdução; 1 O Direito Administrativo do Estado Regulador; 1.1 Breves considerações sobre os modelos de Estado; 1.20 modelo de Estado regulador e as transformações do Direito Administrativo; 2 Desafios do Direito Administrativo no Estado Regulador; 2.1 Pluralismo jurídico, discricionariedade e a escolha regulatória; 2.2 Instrumentos para busca da eficiência na escolha regulatória; 2.3 A garantia de direitos fundamentais nos ambientes regulados; Considerações finais; Referências das fontes citadas

\section{RESUMO}

O Direito Administrativo acompanha as mudanças e transformações do modelo de Estado vigente, de modo que, historicamente, vem passando por constantes transformações. Atualmente, a ascensão do modelo de Estado regulador traz novas tendências para o Direito Administrativo que, com a descentralização de atividades, a diversidade de situações que é instado a enfrentar e as rápidas alterações sociais, políticas, culturais e tecnológicas, passa por novos desafios para a persecução do interesse público. Isso evidencia uma pluralização do Direito e uma valorização da escolha discricionária, a Administração passa, então, a ter um grande poder de escolha, dentre várias situações possíveis, para a prática de seus atos. Isso gera novos desafios para o Direito Administrativo, dentre os quais destacam-se, especialmente, a busca pela eficiência na prática de atos discricionários e a realização imediata de direitos fundamentais em atividades reguladas.

PALAVRAS-CHAVE: Direito Administrativo; Regulação; Escolha Regulatória; Direitos Fundamentais

\footnotetext{
${ }^{1}$ Doutor em Direito do Estado pela Universidade Federal do Paraná, professor do Programa de PósGraduação em Direito da Pontifícia Universidade Católica do Paraná, Curitiba/PR. Advogado, email: blanchet@blanchet.adv.br.

2 Especialista em Direito Administrativo pelo Instituto de Direito Romeu Felipe Bacellar. Mestrando em Direito Econômico e Desenvolvimento pela Pontifícia Universidade Católica do Paraná, Curitiba/PR. Advogado, email: rrbacellar@hotmail.com.
} 
BLANCHET, Luiz Alberto; BACELLAR, Roberto Ramos. Desafios do direito administrativo no estado regulador. Revista Eletrônica Direito e Política, Programa de Pós-Graduação Stricto Sensu em Ciência Jurídica da UNIVALI, Itajaí, v.12, n.3, 30 quadrimestre de 2017. Disponível em: www.univali.br/direitoepolitica - ISSN 1980-7791

\section{ABSTRACT}

Administrative Law accompanies the changes and transformations of the current state model, so that, historically, it has been undergoing constant transformations. Nowadays, the rise of the regulatory state model brings new trends to Administrative Law which, with the decentralization of activities, the diversity of situations it is urged to face and the rapid social, political, cultural and technological changes, presents new challenges for the pursuit of the public interest. This evidences a pluralization of the Law and a valuation of the discretionary choice, the Administration then have a higher power of choice, among several possible situations, for the practice of its acts. This creates new challenges for Administrative Law, among which are the search for efficiency in the practice of discretionary acts and the immediate realization of fundamental rights in regulated activities.

KEYWORDS: Administrative Law; Regulation; Regulatory Choice; Fundamental Rights

\section{INTRODUÇÃO}

O Direito Administrativo tipicamente acompanha as mudanças e transformações no modelo de Estado vigente, fato esse que é facilmente verificável pela própria evolução histórica da matéria. Do Estado absoluto ao Estado social, o Direito Administrativo sempre desempenhou diferentes papéis.

Atualmente, a implementação do chamado Estado regulador representa relevantes alterações no Direito Administrativo.

Marcado especialmente pela tentativa de reduzir o tamanho do Estado, entregando parte das atividades à iniciativa privada e descentralizando funções administrativas entre entes estatais, o Estado regulador passa do papel de prestador de serviços, para assumir a figura de gestor.

Surgem, com isso, agências reguladoras e entes dotados de funções administrativas típicas regulatórias. O Estado passa, assim, a fiscalizar, gerir, regular e fomentar setores da economia.

Disso decorre que o Direito Administrativo passa a ser aplicado por uma diversidade de entes, cada um visando suas competências específicas e adequando-se às necessidades técnicas e jurídicas do setor econômico regulado. Esse fato, somado ao fenômeno da pluralização do Direito, conduz a uma 
BLANCHET, Luiz Alberto; BACELLAR, Roberto Ramos. Desafios do direito administrativo no estado regulador. Revista Eletrônica Direito e Política, Programa de Pós-Graduação Stricto Sensu em Ciência Jurídica da UNIVALI, Itajaí, v.12, n.3, $3^{\circ}$ quadrimestre de 2017. Disponível em: www.univali.br/direitoepolitica - ISSN 1980-7791

importante alteração do Direito Administrativo: já não há um único regime, global e unívoco que possa ser aplicado indistintamente a todos.

Visando acompanhar as rápidas transformações da atualidade e as especificidades de cada setor econômico, a Lei passa a conferir aos entes reguladores um largo campo de discricionariedade, definindo suas competências com base em princípios, em termos genéricos e conceitos jurídicos indeterminados. Assim, cada ente com competência regulatória acaba por adotar seus próprios princípios e parâmetros de atuação, agindo com uma larga escala de discricionariedade. Surge, com isso, a chamada escolha regulatória.

É nesse ponto que se evidenciam os desafios do Direito Administrativo no Estado regulador: se os entes estão dotados de maior discricionariedade, com atuação balizada por princípios e termos genéricos, e se já não se pode falar em um regime unívoco e global para todos, como balizar escolhas discricionárias eficientes, geradas por critérios sólidos e aptas a atender ao interesse público?

Diante desse primeiro desafio, ganham destaque a aproximação do Direito Administrativo com (a) a teoria da ponderação dos princípios e (b) a utilização de instrumentos de Direito Econômico. Ambos os instrumentos representam meios de se buscar escolhas eficientes, possibilitando escolhas regulatórias sérias e comprometidas com o interesse público.

Entretanto, não basta que a escolha regulatória seja eficiente e legítima. Muitas das áreas reguladas pelo Estado envolvem o atendimento direto a direitos fundamentais. Nesses casos, a escolha regulatória deve, ainda, estar apta a atender esses direitos em sua dimensão multifuncional.

Assim, surge o segundo grande desafio do Direito Administrativo: exercer a atividade regulatória garantindo a aplicabilidade imediata dos direitos fundamentais.

Evidentemente esses não são os únicos desafios nem as únicas soluções do Direito Administrativo nesse novo modelo de Estado, entretanto, se faz necessário um recorte metodológico a fim de delimitar o tema. Por essa razão, no presente 
BLANCHET, Luiz Alberto; BACELLAR, Roberto Ramos. Desafios do direito administrativo no estado regulador. Revista Eletrônica Direito e Política, Programa de Pós-Graduação Stricto Sensu em Ciência Jurídica da UNIVALI, Itajaí, v.12, n.3, $3^{\circ}$ quadrimestre de 2017. Disponível em: www.univali.br/direitoepolitica - ISSN 1980-7791

trabalho, serão analisadas essas duas grandes questões a serem enfrentadas pelo Direito Administrativo.

Diante disso, o objetivo é analisar como o Direito Administrativo chegou ao patamar atual e como se caracteriza no cenário do Estado regulador. Para, então, identificar os dois grandes desafios desse novo Direito Administrativo, analisar as origens e características desses desafios e debater as possíveis soluções para possibilitar escolhas eficientes, democráticas, transparentes e voltadas aos direitos fundamentais.

Para tanto, parte-se de uma breve análise da evolução histórica do Direito Administrativo face aos modelos de Estado, chegando-se até o recente Estado regulador; após, serão analisadas algumas características desse modelo de Estado e de como se desempenha a função administrativa e regulatória nesse modelo, identificando o papel do Direito Administrativo; assim, chega-se a analisar os desafios propostos para, em seguida, traçar considerações, propostas de debate e possíveis soluções para os dois grandes desafios indicados.

\section{DIREITO ADMINISTRATIVO DO ESTADO REGULADOR}

\subsection{BREVES CONSIDERAÇÕES SOBRE OS MODELOS DE ESTADO}

A atividade administrativa não se mantém estanque ao longo do tempo e sempre se amolda para acompanhar as transformações da sociedade. O desempenho da atividade administrativa, como consequência da forma de atuação do Estado é matéria em constante evolução.

No Direito Administrativo isso não é uma novidade e, especialmente por ser intrinsicamente ligado ao modelo de Estado no qual cada sistema normativo se encontra inserido, o Direito Administrativo acompanha as tendências dos ordenamentos jurídicos e as feições assumidas pelo Estado. ${ }^{3}$

\footnotetext{
${ }^{3}$ HACHEM, Daniel Wunder. A maximização dos direitos fundamentais econômicos e sociais pela via administrativa e a promoção do desenvolvimento. Revista Direitos Fundamentais \& Democracia, v. 13, n.13, Curitiba, UniBrasil, p. 340-399, jan./jul. 2013.
} 
BLANCHET, Luiz Alberto; BACELLAR, Roberto Ramos. Desafios do direito administrativo no estado regulador. Revista Eletrônica Direito e Política, Programa de Pós-Graduação Stricto Sensu em Ciência Jurídica da UNIVALI, Itajaí, v.12, n.3, 30 quadrimestre de 2017. Disponível em: www.univali.br/direitoepolitica - ISSN 1980-7791

Isso se verifica desde o Estado absoluto, época em que o Estado nada mais era do que patrimônio do monarca e, portanto, o interesse do Estado era o interesse do rei. A Revolução Francesa e a promulgação de uma carta política em 1791 derrotou as tradições absolutistas ${ }^{4}$, desvinculando Estado e patrimônio do rei. O objetivo, então, passou a ser o de garantir a liberdade dos cidadãos e a não interferência na esfera individual de cada um - liberalismo. ${ }^{5}$

A desvinculação entre interesses do monarca e interesses do Estado demandava a adoção de um novo modelo de gestão e, com isso, se adota o modelo burocrático. Tal modelo objetiva a superioridade técnica e previsibilidade das decisões do Estado, pautando suas decisões na racionalidade, por meio de processos impessoais e pré-definidos. Segundo Max Weber, "a razão decisiva para o progresso da organização burocrática foi sempre a superioridade puramente técnica sobre qualquer outra forma de organização". ${ }^{6}$ Surge, nesse tempo, o instituto da desconcentração do Estado.

O Estado Liberal, entretanto, demandava a prestação de serviços mínimos pelo Estado, que compreendiam, basicamente, a garantia da ordem social e da segurança (poder de polícia) e mínimas condições de estrutura (serviço público).

A evolução histórica - notadamente após a revolução industrial com o surgimento de grandes aglomeradas urbanos e profundas alterações das relações sociais e políticas ${ }^{7}$ - novamente levou o Estado a um novo patamar. O anseio por demandas sociais e garantia de condições mínimas aos cidadãos implicaram no surgimento do Estado social.

\footnotetext{
4 GUERRA, Sérgio. Discricionariedade, regulação e reflexividade: uma nova teoria sobre as escolhas administrativas. 3 ed., Belo Horizonte: Fórum, 2015. p. 36.

5 SCHIER, Adriana da Costa Ricardo. Administração Pública: Apontamento sobre os Modelos de Gestão e Tendências Atuais. In: GUIMARÃOES, Edgar (Coord.). Cenários do Direito Administrativo: Estudos em homenagem ao professor Romeu Felipe Bacellar Filho. Belo Horizonte: Fórum, 2004. p. 22.

6 WEBER, Max. Ensaios de Sociologia. 5 Ed. Rio de Janeiro: LTC, 1982. p. 249.

7 GUERRA, Sérgio. Discricionariedade, regulação e reflexividade: uma nova teoria sobre as escolhas administrativas. p. 49.
} 
BLANCHET, Luiz Alberto; BACELLAR, Roberto Ramos. Desafios do direito administrativo no estado regulador. Revista Eletrônica Direito e Política, Programa de Pós-Graduação Stricto Sensu em Ciência Jurídica da UNIVALI, Itajaí, v.12, n.3, 30 quadrimestre de 2017. Disponível em: www.univali.br/direitoepolitica - ISSN 1980-7791

Focado em garantir o bem estar social e condições dignas de sobrevivência, caracterizava-se pelo intervencionismo e pelo considerável aumento dos serviços e atividades prestadas pelo Estado. O Estado transforma-se em um prestador de serviços, passa a atuar em searas antes próprias da iniciativa privada, desbrava novos setores comerciais, remodela mercados e comanda a renovação de estruturas sociais e econômicas. ${ }^{8}$ A intervenção mais assídua do Estado busca compor os conflitos de interesses de grupos e de indivíduos ${ }^{9}$ que, com as profundas alterações sociais e políticas, também se transformaram.

A intervenção do Estado social, é o que Eros Roberto Grau identifica como "intervenção por absorção ou participação", 10 atribuindo-se diretamente ao Estado e às organizações estatais o desempenho das atividades de modelar a vida social e renovar estruturas econômicas.

O modelo de Estado social, entretanto, acabou tornando o Estado excessivamente grande, de modo que as atividades por ele assumidas já não eram exercidas de forma ideal. O Estado se mostrava ineficiente e seus métodos nem sempre eram exequíveis. ${ }^{11}$

Somado à isso, a elevação dos custos decorrentes da prestação direta de todas as atividades e o consequente aumento de passivos governamentais provenientes de sucessivos prejuízos orçamentários reduziu a capacidade estatal de executar satisfatoriamente os encargos que assumia.12 Apesar de seu considerável tamanho, o aparelho do Estado já não era suficiente para a satisfação pessoal e

8 JUSTEN FILHO, Marçal. O Direito das Agências Reguladoras Independentes. São Paulo: Dialética, 2002. p. 17.

9 GUERRA, Sérgio. Discricionariedade, regulação e reflexividade: uma nova teoria sobre as escolhas administrativas. p. 49.

10 GRAU, Eros Roberto. A Ordem Econômica na Constituição de 1988. 4 ed. São Paulo: Malheiros, 1998. p. 122.

11 FINGER, Ana Cláudia. O Público e o Privado na Administração Pública. In: GUIMARÃOES, Edgar (Coordenador). Cenários do Direito Administrativo: Estudos em homenagem ao professor Romeu Felipe Bacellar Filho. Belo Horizonte: Fórum, 2004. p. 72.

12 JUSTEN FILHO, Marçal. O Direito das Agências Reguladoras Independentes. p. 19. 
BLANCHET, Luiz Alberto; BACELLAR, Roberto Ramos. Desafios do direito administrativo no estado regulador. Revista Eletrônica Direito e Política, Programa de Pós-Graduação Stricto Sensu em Ciência Jurídica da UNIVALI, Itajaí, v.12, n.3, $3^{\circ}$ quadrimestre de 2017. Disponível em: www.univali.br/direitoepolitica - ISSN 1980-7791

direta de todas as necessidades coletivas, era inevitável que se procedesse o descongestionamento de tarefas e a consequente descentralização. ${ }^{13}$

Com isso, se introduz reforma administrativa, conduzindo políticas de implementação de práticas de planejamento e descentralização do Estado, focada na construção de um Estado reduzido e com menor intervenção direta no âmbito econômico. É nesse sentido que Marçal Justen Filho afirma que "a contrapartida da redução da intervenção estatal consiste no predomínio de funções regulatórias. Postula-se que o Estado deveria não mais atuar como agente econômico, mas sim, como árbitro das atividades privadas". ${ }^{14}$ Surge, assim, o Estado regulador.

\subsection{O MODELO DE ESTADO REGULADOR E AS TRANSFORMAÇõeS DO DIREITO ADMINISTRATIVO}

O Estado regulador, então, deixa de exercer diretamente uma série de atividades até então por ele monopolizadas. Em um sentido amplo, isso compreende a quebra de monopólios, a desregulação, a concessão e permissão de serviços públicos e a terceirização. Com isso, a iniciativa privada passa a exercer uma série de atividades até então monopolizadas pelo Estado, como serviços públicos de energia elétrica, telecomunicações, portos, rodovias e outros. Por um lado, o estado se abstém de exercer essas atividades que o particular tem condições de prestar, por outro, assume o papel de coordenar, fiscalizar e fomentar a iniciativa privada, especialmente quando isso for de interesse público. ${ }^{15}$

O Direito Administrativo, então, assume novo papel. A quebra de monopólios estatais com as concessões e permissões de serviços públicos, além do exercício de regulação sobre determinadas atividades econômicas, demandam do Direito Administrativo uma aproximação com a economia e com o direito privado, de modo

13 OTERO, Paulo. Legalidade e Administração Pública: o sentido da vinculação administrativa à juridicidade. Lisboa: Almedina, 2003, p. 148

14 JUSTEN FILHO, Marçal. O Direito das Agências Reguladoras Independentes. p. 21.

15 DI PIETRO, Maria Sylvia. Regulação e Legalidade. In: DI PIETRO, Maria Sylvia (coord.). Direito Regulatório: Temas Polêmicos. 2 ed. Belo Horizonte: Fórum, 2004. p. 35. 
BLANCHET, Luiz Alberto; BACELLAR, Roberto Ramos. Desafios do direito administrativo no estado regulador. Revista Eletrônica Direito e Política, Programa de Pós-Graduação Stricto Sensu em Ciência Jurídica da UNIVALI, Itajaí, v.12, n.3, $3^{\circ}$ quadrimestre de 2017. Disponível em: www.univali.br/direitoepolitica - ISSN 1980-7791

que possa comunicar-se com as necessidades econômicas, aliando-as à uma adequada prestação dos serviços.

A regulação, portanto, "é uma espécie de intervenção estatal, porém, indireta, que alcança atividades econômicas e sociais, visando basicamente a implementação de políticas públicas e a realização dos direitos sociais". ${ }^{16}$

Por conta da descentralização e do papel de coordenardor do Estado surgem autarquias sobre a forma de agências reguladoras (como a Agência Nacional de Energia Elétrica - Aneel; Agência Nacional de Telecomunicações - Anatel; Agência Nacional do Petróleo, Gás Natural e Biocombustíveis - ANP; entre outras) e, além delas, outras autarquias passam a exercer funções regulatórias, como, por exemplo, o Banco Central do Brasil - BACEN. Mais recentemente, até entes privados acabam incumbidos de tarefas típicas de regulação (cite-se, como exemplo, a Câmara de Comercialização de Energia Elétrica - CCEE e o Operador Nacional do Sistema Elétrico - ONS).

Dentro dos objetivos do Estado regulador, Maria Sylvia Zanella Di Pietro, destaca que algumas tendências podem ser apontadas, dentre as quais: (a) criar condições para a participação do cidadão no processo político; (b) privatizar por meios que permitam reduzir o papel do Estado na ordem econômica e social; (c) desregular a economia, aplicando regras de livre concorrência; (d) reservar ao Estado a fiscalização, incentivo, planejamento e regulação; (e) submeter o Estado a normas de Direito Internacional Comunitário; (f) desburocratizar a Administração Pública; e (g) ampliar as técnicas de fomento. ${ }^{17}$

A regulação incide tanto nos serviços públicos como nas atividades econômicas em sentido estrito, em maior ou menor grau a depender da atividade desempenhada e da satisfação do interesse público envolvido. Floriano de Azevedo Marques Neto alerta que, mesmo nos casos em que predomine a liberdade de empresa e não houver nenhuma incidência de regulação estatal "haverá, residual e reativamente,

\footnotetext{
16 GUERRA, Sérgio. Discricionariedade, regulação e reflexividade: uma nova teoria sobre as escolhas administrativas. p. 75.

17 DI PIETRO, Maria Sylvia. Regulação e Legalidade. In: DI PIETRO, Maria Sylvia (coord.). Direito Regulatório: Temas Polêmicos. p. 36.
} 
BLANCHET, Luiz Alberto; BACELLAR, Roberto Ramos. Desafios do direito administrativo no estado regulador. Revista Eletrônica Direito e Política, Programa de Pós-Graduação Stricto Sensu em Ciência Jurídica da UNIVALI, Itajaí, v.12, n.3, $3^{\circ}$ quadrimestre de 2017. Disponível em: www.univali.br/direitoepolitica - ISSN 1980-7791

alguma incidência de regulação estatal seja no âmbito da proteção ambiental, seja ainda no tocante à defesa do consumidor". ${ }^{18}$

Por outro lado, atividades diretamente relacionadas à satisfação de direitos fundamentais acabam sofrendo uma maior intervenção estatal. Notadamente os serviços públicos passam a ser regulados visando garantir a universalidade, a qualidade do serviço, a modicidade tarifária, a acessibilidade e afins.

Usualmente, os serviços públicos estão intrinsicamente ligados à consecução de direitos fundamentais, que, por sua vez, tipicamente possuem "dimensões de eficácia diretamente fruíveis e dimensões de eficácia dependentes da intervenção do legislador. Tais dimensões permitem a escolha entre mais de um meio de concretização". ${ }^{19}$ É o caso, por exemplo, dos serviços de educação e saúde que, dada a considerável relevância dos serviços para o atendimento de direitos fundamentais, são prestados tanto pela iniciativa privada quanto pelo Estado, que passa a exercer regulação sobre os serviços prestados.

Não é difícil notar que as funções e objetivos assumidos pelo Estado regulador, transcendem, em muitos aspectos, as concepções tradicionais do Direito Administrativo.

$\mathrm{Na}$ tentativa de acompanhar as rápidas transformações - sejam tecnológicas, econômicas, culturais, políticas ou sociais - de cada setor regulado da economia o Estado assume funções a cada vez mais complexas que exigem atuação de forma eficiente, inteligente e preparada, considerando a fundo as especificidades de cada setor e, especialmente, considerando os aspectos técnicos e o atendimento ao interesse público ali envolvido.

\footnotetext{
18 MARQUES NETO, Floriano de Azevedo. Limites à Abrangência e à Intensidade da Regulação Estatal. Revista Eletrônica de Direito Administrativo Econômico, Salvador, Instituto de Direito Público da Bahia, no 4, nov/dez 2005, jan 2006. Disponível em <www.direitodoestado.com.br>. Acesso em 21/12/2016.

19 BITENCOURT NETO, Eurico. Vinculação da Administração Pública ao Mínimo Existencial. In: NETTO, Luísa Cristina Pinto e; BITENCOURT NETO, Eurico. (Org.). Direito Administrativo e Direitos Fundamentais: diálogos necessários. Belo Horizonte: Fórum, 2012, p. 161.
} 
BLANCHET, Luiz Alberto; BACELLAR, Roberto Ramos. Desafios do direito administrativo no estado regulador. Revista Eletrônica Direito e Política, Programa de Pós-Graduação Stricto Sensu em Ciência Jurídica da UNIVALI, Itajaí, v.12, n.3, $3^{\circ}$ quadrimestre de 2017. Disponível em: www.univali.br/direitoepolitica - ISSN 1980-7791

Veja-se que um único Estado deve encontrar mecanismos, dentro do Direito Administrativo, para regular uma série de setores econômicos muito diversos, como educação, saúde, telecomunicações, mercado financeiro, concorrência, energia elétrica, petróleo, gás e etc. $E$, além de tudo isso, deve encontrar meios de promover a satisfação à direitos fundamentais.

Na concepção de Daniel Hachem, são as mudanças na configuração política dos Estados que produzem repercussões nos sistemas de Direito Administrativo, de modo que, "ainda que se possa, contemporaneamente, identificar traços comuns de caráter geral entre os distintos ordenamentos, a ponto de se cogitar da formação de um Direito Administrativo global, não há dúvidas de que cada realidade merece uma análise pormenorizada". 20

O objetivo do presente trabalho é exatamente esse, identificar as transformações pelas quais o Direito Administrativo vem passando, debatendo formas de viabilizar que o Estado pratique todos os atos necessários a realizar seus deveres. Dentre as ditas alterações das concepções tradicionais, destacam-se dois grandes desafios que o Direito Administrativo é instado a resolver: praticar escolhas discricionárias eficientes; e concretizar direitos fundamentais - dotados de seu regime jurídico especial - nas atividades reguladas.

\section{DESAFIOS DO DIREITO ADMINISTRATIVO NO ESTADO REGULADOR}

\subsection{PLURALISMO JURÍDICO, DISCRICIONARIEDADE E A ESCOLHA REGULATÓRIA}

Como visto, o Estado regulador se caracteriza pelo descongestionamento das tarefas do Estado, especialmente com descentralização das atividades que deixam de ser por ele diretamente prestadas. Os impactos desse novo modelo, entretanto, não figuram apenas no âmbito da organização administrativa: o próprio Direito

\footnotetext{
20 HACHEM, Daniel Wunder. A maximização dos direitos fundamentais econômicos e sociais pela via administrativa e a promoção do desenvolvimento. Revista Direitos Fundamentais \& Democracia. p. 342.
} 
BLANCHET, Luiz Alberto; BACELLAR, Roberto Ramos. Desafios do direito administrativo no estado regulador. Revista Eletrônica Direito e Política, Programa de Pós-Graduação Stricto Sensu em Ciência Jurídica da UNIVALI, Itajaí, v.12, n.3, $3^{\circ}$ quadrimestre de 2017. Disponível em: www.univali.br/direitoepolitica - ISSN 1980-7791

Administrativo e a função administrativa se transformam e passam a enfrentar novos desafios.

Com a substituição do modelo de "Estado administrativo-burocrático, hierárquico, unitário, centralizado e gestor direto, por um novo tipo de Administração, em que organizações não governamentais e privadas pudessem assumir a gestão de atividades econômicas e sociais antes realizadas pelo Estado"21, já não se tem um único Direito Administrativo, já não se fala em uma única função administrativa, tampouco uma única função regulatória.

Agora, o Estado passa a operar e exercer suas atividades típicas de forma especializada em cada um dos setores regulados: o Bacen tem suas próprias normas de organização, a Aneel coordena sua operação por princípios específicos, enquanto a Anatel tem seus próprios critérios de universalização dos serviços apenas para citar alguns exemplos, que ilustram a diversidade de problemas que devem ser enfrentados pelo Direito Administrativo no Estado regulador.

Dentro de cada um desses universos próprios, o Direito Administrativo atuará de uma determinada maneira, considerando especialmente os interesses a serem protegidos por cada um dos entes reguladores. Nesse ponto, a dimensão quantitativa e a complexidade qualitativa ${ }^{22}$ de cada um dos setores da economia torna o problema complexo.

A complexidade das matérias tratadas, juntamente com a pluralidade de agentes exercendo função administrativa e regulatória torna evidente a descentralização da própria legalidade. Com isso, o Direito monista vem sendo substituído por uma concepção de pluralismo jurídico. ${ }^{23}$

Já não há uma única fonte de normas de Direito Administrativo, já não há mais monopólio do Estado no exercício da função administrativa. Não existe, portanto,

${ }^{21}$ CUÉLLAR, Leila. As Agências Reguladoras e seu Poder Normativo. São Paulo: Dialética, 2001. P. 57-58.

22 JUSTEN FILHO, Marçal. O Direito das Agências Reguladoras Independentes. p. 361.

${ }^{23}$ OTERO, Paulo. Legalidade e Administração Pública: o sentido da vinculação administrativa à juridicidade. Lisboa: Almedina, 2003, p. 148. 
BLANCHET, Luiz Alberto; BACELLAR, Roberto Ramos. Desafios do direito administrativo no estado regulador. Revista Eletrônica Direito e Política, Programa de Pós-Graduação Stricto Sensu em Ciência Jurídica da UNIVALI, Itajaí, v.12, n.3, $3^{\circ}$ quadrimestre de 2017. Disponível em: www.univali.br/direitoepolitica - ISSN 1980-7791

uma única Administração Pública, mas sim, várias Administrações Públicas, ${ }^{24}$ cada uma delas com suas especificidades, com funções específicas ligadas diretamente à satisfação do interesse público envolvido em determinada área de exploração econômica.

Some-se a isso a tecnicidade de cada um desses agentes reguladores descentralizados que, ao exercer a sua própria função administrativa e regulatória devem considerar as especificidades de cada setor, devem possuir competência (legal, técnica e racional) para disciplinar os meios técnicos adequados à realização dos fins impostos à certo segmento econômico. ${ }^{25}$

A pluralidade jurídica, a tecnicidade, o dinamismo das relações sociais, políticas e econômicas atuais, somados à superação da ideia de perfeição da Lei - que já não pode antecipar, prevenir ou solucionar todos os novos riscos que espreitam a modernidade 26 - conduzem a desafios do Direito Administrativo moderno.

A legislação estanque, que visa prever todas as situações possíveis e antever qualquer crise, já não é suficiente. A plenitude da Lei já se mostrou inverídica e, com isso, a vinculação total do administrador à Lei já não é viável para a realização dos fins do Estado regulador.

Chega-se, aqui, a um ponto crucial: a crise da legalidade e o reconhecimento da imperfeição da Lei em si. Paulo Otero defende que, por mais paradoxal que possa ser, somente uma intencional imperfeição e incompletude da Lei pode salvar as leis de uma vigência efêmera. O recurso a enumerações exemplificativas, a fuga para cláusulas gerais, o estabelecimento de critérios materiais de ponderação através do estabelecimento de fins e objetivos de ação, se tornam inevitáveis,

24 OTERO, Paulo. Legalidade e Administração Pública: o sentido da vinculação administrativa à juridicidade. p. 149.

25 JUSTEN FILHO, Marçal. O Direito das Agências Reguladoras Independentes. p. 363.

26 OTERO, Paulo. Legalidade e Administração Pública: o sentido da vinculação administrativa à juridicidade. p. 158 . 
BLANCHET, Luiz Alberto; BACELLAR, Roberto Ramos. Desafios do direito administrativo no estado regulador. Revista Eletrônica Direito e Política, Programa de Pós-Graduação Stricto Sensu em Ciência Jurídica da UNIVALI, Itajaí, v.12, n.3, 30 quadrimestre de 2017. Disponível em: www.univali.br/direitoepolitica - ISSN 1980-7791

deixando para o aplicador administrativo ou jurisdicional a concretização do Direito em si. ${ }^{27}$

Vejamos, por exemplo, a Lei no 9.427, que institui a Agência Nacional de Energia Elétrica - Aneel, definindo, logo no artigo segundo, suas finalidades como "regular e fiscalizar a produção, transmissão, distribuição e comercialização de energia elétrica, em conformidade com as políticas e diretrizes do governo federal". A competência da Agência é definida, de forma geral, pelos termos "regular" e "fiscalizar" - expressões notadamente dotadas de generalidade. Mesmo nos incisos do artigo segundo, ${ }^{28}$ que especificam as competências da agência, ainda se nota grande generalidade e estabelecimento de objetivos de ação com base em critérios vagos e conceitos jurídicos abertos.

Isso aumenta a responsabilidade e a importância dos entes reguladores na consecução de seus objetivos, afinal, agora cabe à esses entes, com base nas diretrizes gerais e nos conceitos jurídicos indeterminados apresentados pela Lei, escolher qual a melhor forma de persecução do interesse público, qual a melhor forma de atendimento aos fins ao qual se destina a entidade e qual a melhor forma de atendimento aos direitos fundamentais envolvidos. A discricionariedade, assim, ganha destaque no Estado regulador.

27 OTERO, Paulo. Legalidade e Administração Pública: o sentido da vinculação administrativa à juridicidade. p. 159.

280 artigo $3^{\circ}$ da Lei no 9.427 especifica outras atribuições da Aneel, entretanto, mantém o caráter de generalidade e exemplificação, indicando apenas fins e objetivos de ação e utilizando termos genéricos. Veja-se, por exemplo: "Art. 30 Além das atribuições previstas nos incisos II, III, V, VI, VII, X, XI e XII do art. 29 e no art. 30 da Lei no 8.987, de 13 de fevereiro de 1995, de outras incumbências expressamente previstas em lei e observado o disposto no §10, compete à ANEEL: (...)

I - implementar as políticas e diretrizes do governo federal para a exploração da energia elétrica e o aproveitamento dos potenciais hidráulicos, expedindo os atos regulamentares necessários ao cumprimento das normas estabelecidas pela Lei no 9.074, de 7 de julho de $1995 ;(\ldots)$

IX - zelar pelo cumprimento da legislação de defesa da concorrência, monitorando e acompanhando as práticas de mercado dos agentes do setor de energia elétrica; (...)

XVII - estabelecer mecanismos de regulação e fiscalização para garantir o atendimento à totalidade do mercado de cada agente de distribuição e de comercialização de energia elétrica, bem como à carga dos consumidores que tenham exercido a opção prevista nos arts. 15 e 16 da Lei no 9.074, de 7 de julho de $1995 ;(\ldots)$

XIX - regular o serviço concedido, permitido e autorizado e fiscalizar permanentemente sua prestação. (...)". 
BLANCHET, Luiz Alberto; BACELLAR, Roberto Ramos. Desafios do direito administrativo no estado regulador. Revista Eletrônica Direito e Política, Programa de Pós-Graduação Stricto Sensu em Ciência Jurídica da UNIVALI, Itajaí, v.12, n.3, $3^{\circ}$ quadrimestre de 2017. Disponível em: www.univali.br/direitoepolitica - ISSN 1980-7791

O poder discricionário, na acepção de Celso Antônio Bandeira de Mello difere-se da atuação plenamente vinculada da administração pública por ser esta a única escolha possível, enquanto, aquela, resulta para o administrador um campo de liberdade quanto a maneira de proceder no caso concreto. O autor prossegue afirmando que, em realidade, "o chamado poder discricionário tem que ser simplesmente o cumprimento do dever de alcançar a finalidade legal. Só assim poderá ser corretamente entendido e dimensionado, compreende-se, então, que o que há é um dever discricionário antes que um poder discricionário". ${ }^{29}$

O Direito, já sem trazer todas as respostas e inapto a atender aos rápidos anseios da sociedade moderna especialmente se considerada a velocidade da evolução tecnológica e das alterações das necessidades humanas, e privilegiando a discricionariedade administrativa, abre espaço para a chamada "escolha regulatória". Diogo de Figueiredo Moreira Neto a define como uma discricionariedade a partir do âmbito operativo no manejo de processos, como uma resposta multifuncional aos grandes desafios postos pela complexidade, tecnicidade e mutabilidade contemporânea, tudo visando possibilitar "a tomada de decisão mais adequada para os problemas gerenciais enfrentados pela administração pública, tanto a estatal como a extraestatal, o que vale dizer: para implementar soluções que incrementem a eficiência das escolhas públicas com vistas à realização da boa administração". ${ }^{30}$

A regulação, para alcançar seus objetivos deve perseguir o equilíbrio sistêmico dos setores regulados, baseando-se em uma visão prospectiva, afastando-se das decisões de momento e insustentáveis, a base da escolha regulatória, então, deve ser a preponderância técnica, reduzida à pura discricionariedade. ${ }^{31}$

29 MELLO, Celso Antônio Bandeira de. Discricionariedade e controle judicial. São Paulo: Malheiros, 2001, p. 9-14.

30 MOREIRA NETO, Diogo de Figueiredo. Discricionariedade Administrativa das Autoridades Reguladoras e Aplicação das Noras Punitivas. Revista de Direito Administrativo, v. 254, mai/ago. 2010. p. 95-108.

31 GUERRA, Sérgio. Discricionariedade, regulação e reflexividade: uma nova teoria sobre as escolhas administrativas. p. 75. 
BLANCHET, Luiz Alberto; BACELLAR, Roberto Ramos. Desafios do direito administrativo no estado regulador. Revista Eletrônica Direito e Política, Programa de Pós-Graduação Stricto Sensu em Ciência Jurídica da UNIVALI, Itajaí, v.12, n.3, $3^{\circ}$ quadrimestre de 2017. Disponível em: www.univali.br/direitoepolitica - ISSN 1980-7791

Aqui reside outra questão de grande relevância para a escolha regulatória: o dever de atendimento ao interesse público com eficiência. Não é foco deste trabalho aprofundar o tema da eficiência e boa administração, entretanto, algumas breves considerações são necessárias.

A eficiência é associada a uma série de noções multifuncionais e distintas, ou seja: possui várias dimensões baseadas em conteúdos distintos. Fernando Leal identifica a eficiência sob quatro distintas dimensões, sendo (a) eficiência econômica, vinculada à economicidade; (b) eficiência de resultado, que visa o alcance dos fins buscados pelo agente; (c) eficiência de qualidade, que demanda atendimento satisfatório dos resultados; e, por fim, (d) eficiência jurídica, que agrega exigências de diversas áreas do saber, de modo que "não basta mirar os custos; há de se considerar sempre as finalidades e o atendimento de certos requisitos materiais mínimos para que esteja realizado o dever de eficiência. A eficiência pressupõe economicidade, mas vai além dela". 32

Inerente à própria atividade administrativa, a eficiência também é essencial à escolha regulatória. O que evidencia, então, um grande desafio ao Direito Administrativo: a busca de instrumentos aptos a balizar escolhas discricionárias eficientes.

Diante disso, destacam-se dois pontos relevantes na busca para a eficiência no Direito Administrativo do Estado regulador: a aproximação com a economia e a ponderação de princípios.

\subsection{INSTRUMENTOS PARA BUSCA DA EFICIÊNCIA NA ESCOLHA REGULATÓRIA}

Se agora a administração recebe da Lei uma maior esfera de atuação, com disposições gerais e exemplificativas que vão guiar sua atuação, deixando margens para uma escolha discricionária que, como visto, deve ser eficiente, ganham

\footnotetext{
32 LEAL, Fernando. Propostas para uma abordagem teórico-metodológica do dever constitucional de eficiência. 2008. Revista Eletrônica de Direito do Estado. Salvador, ago./set./out. 2008. Disponível em: <http://www.direitodoestado.com/revista/REDAE-15-AGOSTO-2008FERNANDO\%20LEAL.pdf $>$. Acesso em 20/12/2016. p. 4-5.
} 
BLANCHET, Luiz Alberto; BACELLAR, Roberto Ramos. Desafios do direito administrativo no estado regulador. Revista Eletrônica Direito e Política, Programa de Pós-Graduação Stricto Sensu em Ciência Jurídica da UNIVALI, Itajaí, v.12, n.3, $3^{\circ}$ quadrimestre de 2017. Disponível em: www.univali.br/direitoepolitica - ISSN 1980-7791

destaque instrumentos jurídicos e interdisciplinares que podem ser utilizados pela Administração para balizar a sua atuação. Destacam-se, para os fins deste artigo, a teoria da ponderação de princípios e a utilização de instrumentos do direito econômico.

O modelo econômico estatal baseado na escolha regulatória, favorecedor da discricionariedade administrativa em detrimento da Lei rígida que se propunha a prever todas as situações possíveis, é caracterizado pela busca de uma "atuação eficiente e com foco no bem-estar social mediante ponderação nos conflitos distributivos, à luz de princípios - não apenas regras - que trabalham com categorias econômicas". 33

Dessa afirmação destacam-se dois pontos relevantes: (a) o modelo econômico é caracterizado por conflitos distributivos; e (b) o modelo econômico é baseado em princípios. Cabe, então, analisar a relevância desses dois pontos para o Direito Administrativo do Estado regulador.

Sob um primeiro enfoque, a afirmação de que o modelo econômico é baseado em conflitos distributivos evidencia a aproximação entre Direito e economia.

A utilização de instrumentos da economia pelo Direito e o surgimento do chamado Direito Econômico, parte do pressuposto de que os instrumentos tradicionais do Direito já não são suficientes para compreender adequadamente as relações entre Direito e economia. O Direito tradicional não basta para proporcionar um planejamento econômico adequado, tampouco, realizar análises de impacto eficientes a balizar as decisões tomadas.

Diante disso, o Direito Econômico e a análise econômica do direito ganham relevância como ponto de interseção entre Direito e Economia, dando função ativa à Lei e ao Direito, permitindo conhecer seus efeitos, consequências práticas e moldando instituições aptas a implementar o desenvolvimento.

33 GUERRA, Sérgio. Discricionariedade, regulação e reflexividade: uma nova teoria sobre as escolhas administrativas. p. 73-74. 
BLANCHET, Luiz Alberto; BACELLAR, Roberto Ramos. Desafios do direito administrativo no estado regulador. Revista Eletrônica Direito e Política, Programa de Pós-Graduação Stricto Sensu em Ciência Jurídica da UNIVALI, Itajaí, v.12, n.3, $3^{\circ}$ quadrimestre de 2017. Disponível em: www.univali.br/direitoepolitica - ISSN 1980-7791

O Direito, ao estabelecer regras de conduta, deverá levar em conta impactos econômicos que derivarão dessas normas, os efeitos sobre a distribuição ou alocação de recursos e os incentivos que influenciam os agentes privados. Assim, o Direito influencia e é influenciado pela Economia. No entanto, como alertam Decio Zylberstajn e Rachel Stajn, essa análise seria incompleta se não fossem levadas em conta as instituições, entendidas como conjunto de regras e organizações que regulam relações sociais. ${ }^{34}$

De modo que, segundo os autores, "a análise conjunta do Direito, da Economia e das Organizações tem relevância por possibilitar entendimento mais profundo da complexidade da realidade, permitindo o emprego de aparato metodológico profícuo para a discussão crítica de temas de relevante interesse social". ${ }^{35}$

Nesse contexto o Direito Econômico pode ser visto como uma ferramenta de construção institucional, pois, de um lado o desenvolvimento depende de boas decisões políticas e, de outro, depende da forma como o direito molda as estruturas institucionais para converter as decisões políticas em realidade, representando uma "variável importante na determinação da eficácia das políticas de desenvolvimento e, por extensão, no grau de efetividade dos direitos que elas visam garantir e fomentar"36.

Sendo assim, se a modelagem de estruturas institucionais é essencial para a realização dos direitos no plano físico, e se no Estado regulador cabe à Administração - por meio de seus entes reguladores dotados de considerável discricionariedade na prática dos atos a qual são incumbidos - a modelagem das estruturas institucionais, deve, a Administração, valer-se dos instrumentos aptos a garantir a adequada modelagem das instituições, possibilitando efetivar os Direitos que visam garantir.

\footnotetext{
${ }^{34}$ ZYLBERSZTAJN, Decio; STAJN, Rachel. Direito \& Economia: Análise Econômica do Direito e das Organizações. Rio de Janeiro: Elsevier, 2005. p. 3.

35 ZYLBERSZTAJN, Decio; STAJN, Rachel. Direito \& Economia: Análise Econômica do Direito e das Organizações. p. 4.

${ }^{36}$ COUTINHO, Diogo R. O Direito Econômico e a Construção Institucional do Desenvolvimento Democrático. Revista Estudos Institucionais, vol. 2, n.1, p. 217-253, julho 2016.
} 
BLANCHET, Luiz Alberto; BACELLAR, Roberto Ramos. Desafios do direito administrativo no estado regulador. Revista Eletrônica Direito e Política, Programa de Pós-Graduação Stricto Sensu em Ciência Jurídica da UNIVALI, Itajaí, v.12, n.3, $3^{\circ}$ quadrimestre de 2017. Disponível em: www.univali.br/direitoepolitica - ISSN 1980-7791

Em um segundo ponto, se o novo modelo econômico, é baseado em princípios, e se os princípios podem colidir exigindo que um deles ceda em favor de outro em determinado caso concreto, ${ }^{37}$ deve a Administração buscar elementos aptos a permitir uma escolha consciente e eficiente sobre qual princípio deve prevalecer.

Trata-se, aqui, da aplicação de técnica hermenêutica baseada na identificação, valoração e comparação de interesses contrapostos ${ }^{38}$.

A ponderação de princípios na tomada de decisões administrativas, entretanto, não pode ser utilizada desvinculada de critérios e métodos de justificação e tomada de decisão, sob risco de tomada de decisões irracionais, ou de decisões desprovidas de vinculação com seus princípios informadores.

Sobre a ponderação de princípios na tomada de decisões, Fernando Leal defende a racionalização da ponderação pela identificação dos caminhos pelos quais os participantes de um processo de tomada de decisões devem passar, sendo que, a observância de um roteiro de justificação previamente fixado pode contribuir para a racionalidade dos resultados da ponderação. Alerta o autor os métodos podem por um lado "tornar a ponderação mais organizada, transparente, compreensível e clara; por outro, eles podem limitar, mesmo que de maneira fraca, a discricionariedade do tomador de decisões, na medida em que podem reduzir o conjunto de alternativas decisórias disponíveis". ${ }^{39}$

É nesse mesmo sentido que Luís Manuel Fonseca Pires defende que o que confirma ou infirma a legitimidade do ato discricionário - em seu espaço legítimo de discricionariedade administrativa - é o procedimento de ponderação da teoria dos

\footnotetext{
37 ALEXY, Robert. Teoria dos direitos fundamentais. 2. ed. São Paulo: Malheiros, 2014. p. 93.

38 ALEINIKOFF, Alexander. Constitutional Law in the Age of Balancing. 96 Yale Law Journal, v. 943. 1987, p. 945.

39 LEAL, Fernando. Racional ou Hiper-racional? A ponderação de princípios entre o ceticismo e o otimismo ingênuo. A\&C - Revista de Direito Administrativo e Constitucional, n. 58, p. 177209, out./dez. 2014.
} 
BLANCHET, Luiz Alberto; BACELLAR, Roberto Ramos. Desafios do direito administrativo no estado regulador. Revista Eletrônica Direito e Política, Programa de Pós-Graduação Stricto Sensu em Ciência Jurídica da UNIVALI, Itajaí, v.12, n.3, $3^{\circ}$ quadrimestre de 2017. Disponível em: www.univali.br/direitoepolitica - ISSN 1980-7791

princípios. Além de, ainda, sujeitar-se ao controle de seus pressupostos, elementos vinculados, competência, motivo e finalidade. ${ }^{40}$

A teoria da ponderação dos princípios, então, para além de instrumento apto a balizar a melhor escolha para o administrador, também é entendida como elemento essencial à legitimidade do ato discricionário.

Para além da legitimidade, a ponderação é relevante, especialmente, para a própria busca da eficiência em si. Isso por que "os processos de aplicação de princípios colidentes devem buscar uma composição eficiente entre as normas. Neste aspecto, a busca pelo resultado ótimo (eficiência) é um dever estrutural de aplicação de princípios jurídicos". ${ }^{41}$

O que visa a ponderação de princípios é atingir o ótimo de Pareto, situação em que a alocação de recursos melhora a condição de uma das partes, sem piorar a condição de nenhuma outra. ${ }^{42}$ No caso dos princípios, o critério do ótimo de Pareto "impede intervenções negativas em princípios que possam ser evitadas sem custos para outros princípios". 43

O desafio do Direito Administrativo, aqui, é adotar procedimentos de ponderação, de modo a garantir que a aplicação de princípios colidentes seja feita de maneira eficiente, transparente, democrática, e respeitadora do interesse público envolvido na atividade do regulador.

Entretanto, não basta que o Direito Administrativo adote métodos eficientes para balizar a escolha regulatória. Aliado a tudo isso, cabe também ao Direito

\footnotetext{
40 PIRES, Luís Manuel Fonseca. Controle judicial da discricionariedade administrativa: dos conceitos jurídicos indeterminados às políticas públicas. 2 ed., Belo Horizonte: Fórum, 2013, p. 247.

41 LEAL, Fernando. Propostas para uma abordagem teórico-metodológica do dever constitucional de eficiência. Revista Eletrônica de Direito do Estado. p. 18.

42 MACKAAY, Ejan; ROUSSEAU, Stéphane. Análise econômica do direito. 2 ed. São Paulo: Atlas, 2014. p. 122.

43 LEAL, Fernando. Propostas para uma abordagem teórico-metodológica do dever constitucional de eficiência. Revista Eletrônica de Direito do Estado. p. 18.
} 
BLANCHET, Luiz Alberto; BACELLAR, Roberto Ramos. Desafios do direito administrativo no estado regulador. Revista Eletrônica Direito e Política, Programa de Pós-Graduação Stricto Sensu em Ciência Jurídica da UNIVALI, Itajaí, v.12, n.3, $3^{\circ}$ quadrimestre de 2017. Disponível em: www.univali.br/direitoepolitica - ISSN 1980-7791

Administrativo moderno garantir a realização de direitos sociais e fundamentais nos ambientes regulados, o que, constitui um segundo desafio.

\subsection{A GARANTIA DE DIREITOS FUNDAMENTAIS NOS AMBIENTES REGULADOS}

O segundo grande desafio que o Direito Administrativo do Estado regulador deve enfrentar é a garantia de direitos fundamentais em ambientes regulados.

Muitas das atividades exercidas no Estado regulador estão intrinsicamente ligadas à realização de direitos fundamentais, como, por exemplo, educação, saúde e moradia. Nos casos em que a concretização de direitos fundamentais está envolvida, não basta que um ato regulatório seja praticado com eficiência e legitimidade, mas sim, que efetivamente concretize esses direitos.

O desafio surge com o regime jurídico especial conferido aos direitos fundamentais, caracterizado, especialmente, pela proteção ampliada conferida pela Constituição da República. A importância conferida a esses direitos se justifica por representarem o "o conjunto de valores ou decisões axiológicas básicas de uma sociedade, revestidas da máxima normatividade de que gozam as disposições constitucionais". 44

Do regime jurídico especial conferido aos direitos fundamentais destaca-se, para o propósito do presente trabalho, a sua aplicabilidade imediata superando o "mito" de que tais direitos necessitam de regulamentação de seu conteúdo e políticas de alto custo para sua implementação ${ }^{45}$.

A aplicabilidade imediata consiste em determinação constitucional estabelecendo que "todas as disposições que consagram direitos e garantias constitucionais

\footnotetext{
44 HACHEM, Daniel Wunder. Tutela administrativa efetiva dos direitos fundamentais sociais: por uma implementação espontânea, integral e igualitária. Curitiba, 2014. 614 f. Tese (Doutorado) - Programa de Pós-Graduação em Direito, Universidade Federal do Paraná. p. 67.

45 HACHEM, Daniel Wunder. A dupla titularidade (individual e transindividual) dos direitos fundamentais econômicos, sociais, culturais e ambientais. Revista Direitos Fundamentais \& Democracia, v. 14, n. 14.1, Curitiba, UniBrasil, p. 618-688, ago./dez. 2013. p. 621.
} 
BLANCHET, Luiz Alberto; BACELLAR, Roberto Ramos. Desafios do direito administrativo no estado regulador. Revista Eletrônica Direito e Política, Programa de Pós-Graduação Stricto Sensu em Ciência Jurídica da UNIVALI, Itajaí, v.12, n.3, $3^{\circ}$ quadrimestre de 2017. Disponível em: www.univali.br/direitoepolitica - ISSN 1980-7791

vinculam diretamente os Poderes Públicos (Executivo, Legislativo e Judiciário)".46 Como integrantes da Administração Pública e executores da função administrativa, os entes reguladores não escapam à essa norma.

Assim, evidencia-se o desafio aqui exposto ao Direito Administrativo: conferir aplicabilidade imediata aos direitos fundamentais envolvidos na prestação dos serviços regulados.

A aplicabilidade imediata importa em um direito a uma ação positiva do Estado, o que Robert Alexy conceitua como direito a uma prestação. Segundo o autor o direito a prestações se associa a ideia de um "direito a algo que o titular do direito poderia obter de outras pessoas privadas se dispusesse de meios financeiros suficientes", alertando, em seguida, que o conceito não se limita a isso porque engloba, também, aos direitos a prestação normativas. ${ }^{47}$

Então, o dever de o Estado assegurar prestações materiais não é a única forma consagradora da eficácia de direitos fundamentais, Eurico Bittencourt Neto identifica, para além da prestação material, outros exemplos de eficácia direta de uma norma de direito fundamental, como, por exemplo (a) eficácia negativa; (b) consequências jurídicas decorrentes da dimensão objetiva; (c) dever de legislar; (d) justificação para a declaração de inconstitucionalidade por omissão; (e) justificação para impetração de mandado de segurança; (f) justificação para inconstitucionalidade por ação; (g) possibilidade de responsabilização do Estado por omissão; (h) dever de que tais direitos sejam considerados como guias de interpretação de normas; (i) emissão de força irradiante; (j) justificação para restrições à liberdade; (k) eficácia derrogatória de atos anteriores. ${ }^{48}$

A pluralidade de funções dos direitos fundamentais é chamada, por Daniel Hachem de multifuncionalidade. Segundo o autor, quando observados em sentido amplo,

\footnotetext{
46 HACHEM, Daniel Wunder. Tutela administrativa efetiva dos direitos fundamentais sociais: por uma implementação espontânea, integral e igualitária. p. 68.

47 ALEXY, Robert. Teoria dos direitos fundamentais. p. 442.

48 BITENCOURT NETO, Eurico. Vinculação da Administração Pública ao Mínimo Existencial. In: NETTO, Luísa Cristina Pinto e; BITENCOURT NETO, Eurico. (Org.). Direito Administrativo e Direitos Fundamentais: diálogos necessários. p. 158.
} 
BLANCHET, Luiz Alberto; BACELLAR, Roberto Ramos. Desafios do direito administrativo no estado regulador. Revista Eletrônica Direito e Política, Programa de Pós-Graduação Stricto Sensu em Ciência Jurídica da UNIVALI, Itajaí, v.12, n.3, 30 quadrimestre de 2017. Disponível em: www.univali.br/direitoepolitica - ISSN 1980-7791

os direitos fundamentais se desdobram em várias funções, como (a) defesa contra investidas do Estado; (b) prestações materiais fornecidas no mundo dos fatos; e (c) de prestações normativas, que envolvem desde a proteção contra ações de particulares como a criação de órgãos, instituições e procedimentos que viabilizem o desempenho das demais funções. ${ }^{49}$

As garantias de prestação de direitos fundamentais se expandem para muito além da prestação material, uma vez que, possuindo dimensões de eficácia diretamente fruíveis, permitem a escolha entre mais de um meio de concretização. Aqui reside outro desafio para o Direito Administrativo do Estado regulador, como consequência do princípio democrático e do pluralismo jurídico, as escolhas realizadas pelo administrador devem respeitar a vontade das maiorias, sem desconsiderar valores constitucionalmente consagrados ${ }^{50} \mathrm{e}$, além de tudo, levando em conta a necessária análise técnica específica para cada setor, típica do Estado regulador.

Importante frisar que o respeito à vontade das maiorias não significa obediência irrestrita à essa vontade. Note-se que, não incomum, a vontade das maiorias pode ser contrária realização de direitos fundamentais, hipótese que enseja entendimento de que os direitos fundamentais estão inseridos em um campo designado contramajoritário. Ou seja: devem ser garantidos mesmo contra a vontade das maiorias eventuais, mesmo que democraticamente investidas no exercício do poder. ${ }^{51}$

O desafio do Direito Administrativo torna-se mais complexo quando se leva em conta o grau de satisfação que deve ser dado ao direito fundamental. Daniel Hachem defende a ascensão de um Direito Administrativo Social, atento à

49 HACHEM, Daniel Wunder. A dupla titularidade (individual e transindividual) dos direitos fundamentais econômicos, sociais, culturais e ambientais. Revista Direitos Fundamentais \& Democracia, v. 14, n. 14.1, Curitiba, UniBrasil, p. 618-688, ago./dez. 2013. p. 628.

50 BITENCOURT NETO, Eurico. Vinculação da Administração Pública ao Mínimo Existencial. In: NETTO, Luísa Cristina Pinto e; BITENCOURT NETO, Eurico. (Org.). Direito Administrativo e Direitos Fundamentais: diálogos necessários. p. 160.

51 FONTE, Felipe de Melo. Políticas públicas e direitos fundamentais: elementos de fundamentação do controle jurisdicional de políticas públicas no Estado Democrático de Direito. São Paulo: Saraiva, 2013. p. 205. 
BLANCHET, Luiz Alberto; BACELLAR, Roberto Ramos. Desafios do direito administrativo no estado regulador. Revista Eletrônica Direito e Política, Programa de Pós-Graduação Stricto Sensu em Ciência Jurídica da UNIVALI, Itajaí, v.12, n.3, 30 quadrimestre de 2017. Disponível em: www.univali.br/direitoepolitica - ISSN 1980-7791

"necessidade de concretização do Estado social e Democrático de Direito a partir de uma atuação estatal interventiva nos domínios econômico e social"52, garantindo um atendimento máximo ao direito fundamental em questão, de modo que o chamado "mínimo existencial" seja o piso mínimo de satisfação desses direitos, e não o teto máximo.

Essa concepção rejeita a teoria de atuação subsidiária do Estado ${ }^{53}$, de modo que, seguindo essa linha, o Estado deve assumir papel ativo na promoção de políticas públicas e prestação de serviços públicos aptos a promoverem, de forma máxima, os direitos fundamentais.

Assim, mesmo com a tentativa de descongestionamento das tarefas estatais, é defeso ao Estado abster-se de garantir a eficácia de direitos fundamentais no plano fático, de modo que o Direito Administrativo enfrenta novo desafio com a promoção, para além do mínimo e em caráter multifuncional, dos direitos fundamentais.

A questão relevante é que, para a promoção dos direitos fundamentais, o Estado assume basicamente duas tarefas principais: a prestação de serviços públicos e a implementação de políticas públicas.

As políticas públicas, aqui, se adotado conceito abrangente tal qual o defendido por Ana Paula de Barcellos, envolvem "não apenas a prestação de serviços ou o desenvolvimento de atividades executivas diretamente pelo Estado, como também sua atuação normativa, reguladora e de fomento, nas mais diversas áreas". ${ }^{54}$

Veja-se que, aqui, a instituição de políticas públicas, segundo o conceito amplo, aproxima-se muito da própria tarefa regulatória do Estado, especialmente

52 HACHEM, Daniel Wunder. A maximização dos direitos fundamentais econômicos e sociais pela via administrativa e a promoção do desenvolvimento. Revista Direitos Fundamentais \& Democracia. p. 355.

53 Sobre as críticas à subsidiariedade, ver: GABARDO, Emerson. Interesse Público e Subsidiariedade: o Estado e a sociedade civil para além do bem e do mal. Belo Horizonte: Fórum, 2009.

54 BARCELLOS, Ana Paula de. Constitucionalização das políticas públicas em matéria de direitos fundamentais: o controle político-social e o controle jurídico no espaço democrático. In: Ingo Wolfgang Sarlet; Luciano Benetti Timm (Orgs.). Direitos fundamentais: orçamento e reserva do possível. 2. ed. Porto Alegre: Livraria do Advogado, 2010. p. 102. 
BLANCHET, Luiz Alberto; BACELLAR, Roberto Ramos. Desafios do direito administrativo no estado regulador. Revista Eletrônica Direito e Política, Programa de Pós-Graduação Stricto Sensu em Ciência Jurídica da UNIVALI, Itajaí, v.12, n.3, $3^{\circ}$ quadrimestre de 2017. Disponível em: www.univali.br/direitoepolitica - ISSN 1980-7791

considerando seu caráter normativo e a utilização do Direito Administrativo como modelador de instituições aptas a realizar o interesse público.

Considerando, então, as concepções que foram até aqui adotadas, o Direito Administrativo do Estado regulador se configura por seu caráter plural, sendo praticado por uma diversidade de entes, cada qual com seu "próprio" Direito Administrativo que é aplicado considerando as especificidades e peculiaridades de cada um dos setores regulados. Sendo assim, o desafio que cada um desses diferentes Direitos Administrativos deve enfrentar é o de assumir papel ativo como instrumento institucional de realização dos direitos fundamentais em seu caráter multifuncional, abandonando-se a antiga ideia de entrave legal e burocrático.

\section{CONSIDERAÇÕES FINAIS}

O Estado regulador conduziu a um desenho institucional de Estado enxuto, que não mais se incumbe de prestar diretamente todos os serviços ou de garantir diretamente os direitos, mas, entrega parte das atividades administrativas à iniciativa privada, assumindo papel de coordenador das atividades.

Surgem, com isso, agências reguladoras e demais entidades que exercem regulação sobre determinado setor econômico, ficando incumbidas de garantir o atendimento do interesse público específico voltado para aquela atividade.

A regulação acaba por acarretar na pluralidade do Direito, que já não é oriundo de uma única fonte, mas sim, irradia de diversos agentes diferentes. O Direito Administrativo, que sempre acompanha as transformações pelas quais passa o modelo de Estado, é especialmente afetado pelo fenômeno da pluralização.

A multiplicidade de agentes exercendo funções administrativas - e, portanto, praticando o Direito Administrativo - de modo específico para cada setor regulado, considerando as normas e peculiaridades daquele setor, conduz à pluralização do Direito Administrativo: já não há um único Direito Administrativo global e unitário, mas sim, vários que operam de forma específica para cada entidade e setor regulado. 
BLANCHET, Luiz Alberto; BACELLAR, Roberto Ramos. Desafios do direito administrativo no estado regulador. Revista Eletrônica Direito e Política, Programa de Pós-Graduação Stricto Sensu em Ciência Jurídica da UNIVALI, Itajaí, v.12, n.3, $3^{\circ}$ quadrimestre de 2017. Disponível em: www.univali.br/direitoepolitica - ISSN 1980-7791

A pluralização do Direito no Estado regulador, aliada às rápidas transformações técnicas, políticas, culturais e sociais de cada setor econômico, acabam por favorecer a discricionariedade dos agentes reguladores. Para acompanhar a velocidade das transformações os agentes reguladores, e o Direito Administrativo específico para cada área de atuação, são dotados de considerável discricionariedade para a escolha de seus atos. Com isso, e somado à tecnicidade da regulação, e à especificidade e complexidade das relações políticas, culturais e sociais da atualidade, surge a chamada "escolha regulatória".

A escolha regulatória, entretanto, importa em novos desafios para a Administração, ganhando destaque a possibilidade de utilização de instrumentos multidisciplinares para balizar a escolha do administrador. Para os fins do presente trabalho, o primeiro grande problema analisado foi a necessidade de encontrar meios para proporcionar escolhas discricionárias eficientes e, para tanto, foram analisados os institutos do (a) teoria da ponderação de princípios e do (b) Direito Econômico.

(a) A teoria da ponderação dos princípios se destaca com a pluralização do Direito, momento em que a competência dos agentes regulatórios é cada vez mais dotada de generalidade e amplitude. A utilização de conceitos jurídicos indeterminados e a utilização de princípios para delimitação das funções dos reguladores importa no fato de que os agentes são cada vez mais instados a exercer escolhas sobre quais princípios consagrar em determinado caso específico, de modo que essa escolha deve ser orientada por uma metodologia que garanta critérios claros e transparentes da valoração principiológica realizada pela Administração. Sendo assim, o desafio da administração é incluir, no Direito Administrativo, critérios hábeis a proporcionar escolhas eficientes balizadas em metodologia clara, treinando os agentes públicos para aplicarem, de forma correta, a metodologia escolhida.

(b) Os institutos de Direito Econômico ganham destaque com sua aproximação das relações entre Direito e Economia - essencial para que a escolha regulatória seja dotada da necessária tecnicidade -, permitindo ao Administrador o devido conhecimento do funcionamento de setores econômicos e a tomada de decisões 
BLANCHET, Luiz Alberto; BACELLAR, Roberto Ramos. Desafios do direito administrativo no estado regulador. Revista Eletrônica Direito e Política, Programa de Pós-Graduação Stricto Sensu em Ciência Jurídica da UNIVALI, Itajaí, v.12, n.3, $3^{\circ}$ quadrimestre de 2017. Disponível em: www.univali.br/direitoepolitica - ISSN 1980-7791

mais conscientes e controladas. Uma vez que os atos praticados por agentes reguladores impactam diretamente nas relações econômicas, a escolha regulatória deve ser balizada por instrumentos que estejam aptos a proporcionar a consagração, no mundo dos fatos, dos interesses públicos envolvidos em cada setor específico da regulação. O desafio da Administração, aqui, é utilizar o Direito Administrativo como instituto modelador de condutas que reflitam, na prática, o atendimento ao interesse público e a consagração de direitos.

O segundo, e talvez maior, desafio do Direito Administrativo, surge com a constatação de que muitas das tarefas realizadas diretamente ou reguladas pela Administração, estão intrinsicamente ligadas a realização de direitos fundamentais.

Os direitos fundamentais, por sua vez, são dotados de aplicabilidade imediata, sendo exigíveis em sua multifuncionalidade independente de regulamentação ou Lei - para além de somente prestações materiais. Sendo assim, o desafio do Direito Administrativo é de realizar a atividade administrativa e regulatória de modo a garantir a eficácia de direitos fundamentais em sua multifuncionalidade. Mesmo nas atividades não prestadas diretamente pelo Estado, mas reguladas indiretamente, é dever do Estado atuar de modo que consagre a aplicabilidade imediata desses direitos fundamentais.

A relação entre os dois grandes problemas se torna evidente quando considerado que por um lado cabe ao Direito Administrativo a garantia da multifuncionalidade dos direitos fundamentais; enquanto, por outro lado, cabe ao direito administrativo modelar instituições aptas a proporcionar a consagração fática de interesses públicos, utilizando-se de metodologia adequada para definição de quais princípios serão aplicáveis em cada caso específico.

Ou seja: (1) é dever do Estado garantir a eficácia imediata de direitos fundamentais em sua multifuncionalidade; (2) a garantia desses direitos pode ser realizada por prestações materiais, políticas públicas, serviços públicos e edição de normas; (3) o Direito Administrativo, especialmente pelo ato regulatório, compreende todas essas atividades passíveis de realizar direitos fundamentais; (4) o ato regulatório é dotado de discricionariedade; (5) para realizar direitos 
BLANCHET, Luiz Alberto; BACELLAR, Roberto Ramos. Desafios do direito administrativo no estado regulador. Revista Eletrônica Direito e Política, Programa de Pós-Graduação Stricto Sensu em Ciência Jurídica da UNIVALI, Itajaí, v.12, n.3, $3^{\circ}$ quadrimestre de 2017. Disponível em: www.univali.br/direitoepolitica - ISSN 1980-7791

fundamentais, a escolha discricionária deve ser eficiente; e (6) a eficiência regulatória pode ser alcançada, dentre outros, pela ponderação de princípios e pelo uso de instrumentos do Direito Econômico.

A relação entre a utilização de meios para o balizamento da escolha regulatória eficiente e a consagração dos direitos fundamentais, então, se torna bastante clara: a consagração de direitos fundamentais depende diretamente da adequada utilização do Direito Administrativo como modelador de instituições eficientes.

\section{REFERÊNCIAS DAS FONTES CITADAS}

ALEXY, Robert. Teoria dos direitos fundamentais. 2. ed. São Paulo: Malheiros, 2014.

ALEINIKOFF, Alexander. Constitutional Law in the Age of Balancing. 96 Yale Law Journal, v. 943. 1987.

BARCELLOS, Ana Paula de. Constitucionalização das políticas públicas em matéria de direitos fundamentais: o controle político-social e o controle jurídico no espaço democrático. In: Ingo Wolfgang Sarlet; Luciano Benetti Timm (Orgs.). Direitos fundamentais: orçamento e reserva do possível. 2. ed. Porto Alegre: Livraria do Advogado, 2010.

BITENCOURT NETO, Eurico. Vinculação da Administração Pública ao Mínimo Existencial. In: NETTO, Luísa Cristina Pinto e; BITENCOURT NETO, Eurico. (Org.). Direito Administrativo e Direitos Fundamentais: diálogos necessários. Belo Horizonte: Fórum, 2012.

COUTINHO, Diogo R. O Direito Econômico e a Construção Institucional do Desenvolvimento Democrático. Revista Estudos Institucionais, vol. 2, n.1, p. 217-253, julho 2016.

CUÉLLAR, Leila. As Agências Reguladoras e seu Poder Normativo. São Paulo: Dialética, 2001.

DI PIETRO, Maria Sylvia. Regulação e Legalidade. In: DI PIETRO, Maria Sylvia (coord.). Direito Regulatório: Temas Polêmicos. 2 ed. Belo Horizonte: Fórum, 2004.

FINGER, Ana Cláudia. O Público e o Privado na Administração Pública. In: GUIMARÃOES, Edgar (Coordenador). Cenários do Direito Administrativo: Estudos em homenagem ao professor Romeu Felipe Bacellar Filho. Belo Horizonte: Fórum, 2004. 
BLANCHET, Luiz Alberto; BACELLAR, Roberto Ramos. Desafios do direito administrativo no estado regulador. Revista Eletrônica Direito e Política, Programa de Pós-Graduação Stricto Sensu em Ciência Jurídica da UNIVALI, Itajaí, v.12, n.3, $3^{\circ}$ quadrimestre de 2017. Disponível em: www.univali.br/direitoepolitica - ISSN 1980-7791

FONTE, Felipe de Melo. Políticas públicas e direitos fundamentais: elementos de fundamentação do controle jurisdicional de políticas públicas no Estado Democrático de Direito. São Paulo: Saraiva, 2013.

GABARDO, Emerson. Interesse Público e Subsidiariedade: o Estado e a sociedade civil para além do bem e do mal. Belo Horizonte: Fórum, 2009.

GRAU, Eros Roberto. A Ordem Econômica na Constituição de 1988. 4 ed. São Paulo: Malheiros, 1998.

GUERRA, Sérgio. Discricionariedade, regulação e reflexividade: uma nova teoria sobre as escolhas administrativas. 3 ed., Belo Horizonte: Fórum, 2015.

HACHEM, Daniel Wunder. A dupla titularidade (individual e transindividual) dos direitos fundamentais econômicos, sociais, culturais e ambientais. Revista Direitos Fundamentais \& Democracia, v. 14, n. 14.1, Curitiba, UniBrasil, p. 618-688, ago./dez. 2013.

HACHEM, Daniel Wunder. A maximização dos direitos fundamentais econômicos e sociais pela via administrativa e a promoção do desenvolvimento. Revista Direitos Fundamentais \& Democracia, v. 13, n.13, Curitiba, UniBrasil, p. 340399, jan./jul. 2013.

HACHEM, Daniel Wunder. Tutela administrativa efetiva dos direitos fundamentais sociais: por uma implementação espontânea, integral e igualitária. Curitiba, 2014. 614 f. Tese (Doutorado) - Programa de Pós-Graduação em Direito, Universidade Federal do Paraná.

LEAL, Fernando. Propostas para uma abordagem teórico-metodológica do dever constitucional de eficiência. 2008. Revista Eletrônica de Direito do Estado. Salvador, ago./set./out. Disponível em: <http://www.direitodoestado.com/revista/REDAE-15-AGOSTO-2008-

FERNANDO\%20LEAL.pdf > . Acesso em 20/12/2016.

LEAL, Fernando. Racional ou Hiper-racional? A ponderação de princípios entre o ceticismo e o otimismo ingênuo. A\&C - Revista de Direito Administrativo e Constitucional, n. 58, p. 177-209, out./dez. 2014.

MACKAAY, Ejan; ROUSSEAU, Stéphane. Análise econômica do direito. 2 ed. São Paulo: Atlas, 2014.

MARQUES NETO, Floriano de Azevedo. Limites à Abrangência e à Intensidade da Regulação Estatal. Revista Eletrônica de Direito Administrativo Econômico, Salvador, Instituto de Direito Público da Bahia, no 4, nov/dez 2005, jan 2006. Disponível em <www.direitodoestado.com.br>. Acesso em 21/12/2016.

MELLO, Celso Antônio Bandeira de. Discricionariedade e controle judicial. São Paulo: Malheiros, 2001, p. 9-14. 
BLANCHET, Luiz Alberto; BACELLAR, Roberto Ramos. Desafios do direito administrativo no estado regulador. Revista Eletrônica Direito e Política, Programa de Pós-Graduação Stricto Sensu em Ciência Jurídica da UNIVALI, Itajaí, v.12, n.3, $3^{\circ}$ quadrimestre de 2017. Disponível em: www.univali.br/direitoepolitica - ISSN 1980-7791

MOREIRA NETO, Diogo de Figueiredo. Discricionariedade Administrativa das Autoridades Reguladoras e Aplicação das Noras Punitivas. Revista de Direito Administrativo, v. 254, mai/ago. 2010.

OTERO, Paulo. Legalidade e Administração Pública: o sentido da vinculação administrativa à juridicidade. Lisboa: Almedina, 2003, p. 148

PIRES, Luís Manuel Fonseca. Controle judicial da discricionariedade administrativa: dos conceitos jurídicos indeterminados às políticas públicas. 2 ed., Belo Horizonte: Fórum, 2013.

SCHIER, Adriana da Costa Ricardo. Administração Pública: Apontamento sobre os Modelos de Gestão e Tendências Atuais. In: GUIMARÃOES, Edgar (Coord.). Cenários do Direito Administrativo: Estudos em homenagem ao professor Romeu Felipe Bacellar Filho. Belo Horizonte: Fórum, 2004.

WEBER, Max. Ensaios de Sociologia. 5 Ed. Rio de Janeiro: LTC, 1982. p. 249.

JUSTEN FILHO, Marçal. O Direito das Agências Reguladoras Independentes. São Paulo: Dialética, 2002.

ZYLBERSZTAJN, Decio; STAJN, Rachel. Direito \& Economia: Análise Econômica do Direito e das Organizações. Rio de Janeiro: Elsevier, 2005.

Submetido em: agosto de 2017

Aprovado em: outubro de 2017 